\title{
ELABORAÇÃO DO MAPA GEOMORFOLÓGICO DO MUNICÍPIO DE PORTO ALEGRE - RS
}

\author{
ELABORATION OF THE \\ GEOMORPHOLOGICAL MAP OF PORTO \\ ALEGRE MUNICIPALLY - RS
}

Nina Simone Vilaverde Moura e Tielle Soares Dias

nina.moura@ufrgs.br

Departamento de Geografia da UFRGS, Porto Alegre, RS

Resumo

Este trabalho consiste na identificação dos compartimentos de relevo do município de Porto Alegre, capital do estado do Rio Grande do Sul. Nesse sentido, o objetivo desta pesquisa é elaborar um mapeamento geomorfológico, em escala 1:50.000, para identificar as diferentes formas de relevo e os principais aspectos de sua modelagem, litologia e morfogênese. Para tanto, busca-se atingir alguns objetivos específicos, que são: caracterizar o quadro geológico e geomorfológico regional; caracterizar e mapear as diferentes feições de relevo através de seus elementos morfométricos, morfológicos, morfogenéticos e morfocronológicos. A análise segue a proposta de classificação do relevo proposta por Ross (1992), que visa a expressar cartograficamente o relevo, entendendo morfoestrutura como as unidades maiores e morfoescultura para as formas e tipos de relevo contidos em cada morfoestrutura. As atividades de pesquisa abrangem: levantamento bibliográfico; elaboração da base cartográfica digital e de mapas morfométricos; 
interpretação de fotografias aéreas e imagens de satélites; e a criação do mapa de elementos do relevo. No âmbito regional, Porto Alegre está localizada numa região de contato entre unidades morfoesculturais do relevo do RS, sendo ela o Planalto Uruguaio Sulriograndense, constituído por rochas cristalinas e caracterizado por um relevo mais elevado, e as formações de origem sedimentar, referentes à Planície Costeira e ao aporte de sedimentos da Depressão Periférica. Inseridos nessas morfoesculturas, foram identificados os seguintes padrões de relevo: padrão em morros; em colinas; em terraços; em planícies; e em áreas planas de origem antropogênica. As áreas mais elevadas e com maiores declividades correspondem ao padrão de morros localizado na parte central do município, numa faixa de sentido nordeste sudoeste. As áreas mais planas e com menores altitudes correspondem ao padrão de planícies localizado ao sul e ao norte do município.

Palavras-chave: Município de Porto Alegre; mapeamento geomorfológico; relevo.

\section{Abstract}

The aim of this work is to identify relief compartments in Porto Alegre municipality, Rio Grande do Sul State capital. Therefore, this research's objective is to elaborate a geomorphological mapping, scale 1:50.000, to identify different relief structures and the main aspects of its shaping, lithology and morphogenesis. In order to achieve that, one has to characterize the regional geological and geomorphological scene, characterize and map different relief shapes through its morphometric, morphological, morphogenetic and morpho-chronological elements. The analysis follows Ross (1992) and aim to express cartographically the relief in each morphostructure. The following methodology was applied: bibliographical research, digital cartographic base and morphometric maps elaboration, aerial photographs and satellite images analysis and mapping the relief elements. Regarding regional aspects, Porto Alegre is bounded by "Planalto Uruguaio Sulriograndense" (a plateau, a higher relief) which formation consists of crystalline rocks and the "Planície Costeira" (plain, lowland, with sedimentary origin and intake of higher lands sediments from "Depressão Periférica"). The following relief patterns were identified into this morphosculpture: hills; low hills; terrace; plains and flat areas of anthropogenic 
origins. The higher and steeper areas belong to hill patterns located on the municipality's central area, on a northeast-southwest directed stripe. The flatter and lower lands belong to plain patterns located in the south and north of the municipality.

Keywords: geomorphological mapping, Porto Alegre municipality, relief.

\section{Introdução}

O Mapa Geomorfológico do município de Porto Alegre foi desenvolvido no Laboratório de Geografia Física do Departamento de Geografia do Instituto de Geociências da Universidade Federal do Rio Grande do Sul entre os anos de 2007 e 2009 . Esse mapeamento teve o intuito de dar continuidade às pesquisas realizadas anteriormente na Região Metropolitana de Porto Alegre por Fujimoto (1994, 2001) e Fujimoto \& Schmitz (2004). Os trabalhos realizados trataram fundamentalmente de estudos sobre a paisagem local em áreas pertencentes aos municípios de Porto Alegre e Viamão. Tais estudos foram realizados a partir do mapeamento das principais feições de relevo e da elucidação dos processos que operam na sua superfície. Esses processos referem-se à ação marinha, fluvial, continental, eólica, lagunar e à ação humana, que gera e acelera os processos geomorfológicos. Com isso, tratou-se de estudos de compartimentação geomorfológica centrados na dinamicidade da natureza, tornando possível evidenciar as potencialidades e as fragilidades do meio físico e, nesse sentido, fornecer elementos para uma adequada ordenação territorial.

É importante destacar que, em outros momentos, textos e mapeamentos com o objetivo de identificar os compartimentos de relevo e a morfogênese do relevo do estado do Rio Grande do Sul, do município de Porto Alegre ou de uma porção do território de Porto Alegre, foram elaborados. Os estudos referentes ao estado do Rio Grande do Sul contribuíram na construção do entendimento sobre o relevo do município de Porto Alegre, são eles: Müller Filho (1970), Suertegaray (1996) e Suertegaray \& Fujimoto (2004). Merecem destaque os estudos no âmbito regional de Fragoso-Cesar (1982a, 1982b), Fernandes et al (1995) e Philipp et al (1998) quanto à evolução geológica a partir de novas concepções da dinâmica global. Entre os trabalhos de abrangên- 
cia municipal, é importante ressaltar o estudo de Ab'Saber \& Roche (1966) que descreve Porto Alegre sob diversos aspectos, com ênfase na caracterização do sítio urbano. Destaca-se, ainda, a abordagem sobre a evolução geológica e a caracterização geomorfológica realizada no Atlas Ambiental de Porto Alegre, elaborado em 1998, no qual é proposto um mapeamento, em escala 1:100.000, que identifica os diferentes compartimentos e feições de relevo do município de Porto Alegre.

$\mathrm{O}$ objetivo principal desse trabalho refere-se à elaboração de um mapa geomorfológico que represente as diferentes formas de relevo e os principais aspectos de sua modelagem, litologia e morfogênese. Para atingir esse objetivo principal, foi necessário alcançar alguns objetivos mais específicos, que são: caracterizar o quadro geológico e geomorfológico regional para contextualizar a área nos grandes compartimentos do relevo; caracterizar e mapear as diferentes feições de relevo através de seus elementos morfométricos, morfológicos, morfogenéticos e morfocronológicos.

A identificação dos compartimentos de relevos baseia-se em um estudo dos diferentes tamanhos das formas de relevo e sua dinâmica. Os mapeamentos e análises das formas, gênese e dinâmica oferecem subsídios à avaliação do potencial de uso da terra e da fragilidade dos ambientes naturais, em função dos usos atuais e futuros. As formas de relevo têm intrínsecas relações com o processo dinâmico de transformação da natureza, influenciando no modo como a sociedade apropria-se dos recursos naturais. É, portanto, no âmbito de uma análise geomorfológica preocupada em identificar as formas de relevo e compreender a sua evolução que se desenvolveu este trabalho.

A área de estudo abrange todo o território político-administrativo do município de Porto Alegre na escala de 1:50.000. Nesse nível de análise, o tratamento torna-se regional e a escala cartográfica definida é adequada à análise desejada (Figura 1). 


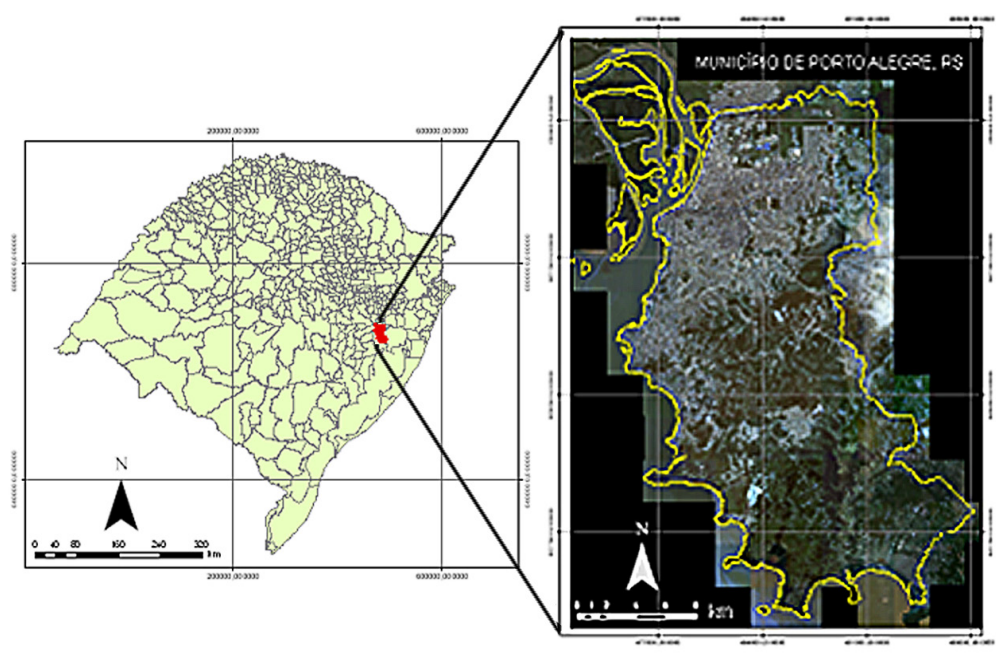

Figura 1: Localização do Município de Porto Alegre em relação ao Estado do Rio Grande do Sul, Brasil.

Elaboração: Laboratório de Geografia Física da UFRGS 2008.

\section{Metodologia e operacionalização}

\subsection{Pressupostos Teóricos e Metodológicos}

O mapeamento realizado segue a proposta de ordenamento dos estudos geomorfológicos proposto por Ab'Saber (1969), procurando caracterizar e descrever as formas de relevo de acordo com os diferentes níveis de escala relacionados aos processos que operam na sua formação. Em seguida, procura articular geologia e geomorfologia, de forma a sistematizar as informações sobre a cronogeomorfologia. Por fim, pretende compreender a dinâmica dos processos morfoclimáticos, pedogenéticos e da ação antrópica.

Em nível conceitual, esse método encara a necessidade de um conceito abrangente das formas de relevo, considerando-as como decorrentes de processos endógenos e exógenos. A ação predominante das forças endógenas forma os elementos morfoestruturais que, para serem interpretados, devem ser analisados a partir dos condicionantes tectônicos. As morfoesculturas correspondem ao modelado de formas geradas sobre diferentes estruturas e sob a ação dos fatores exógenos. 
Nesse sentido, a proposição de Ross (1992) estabelece uma ordem taxonômica para o relevo terrestre, calcado nessas considerações de natureza conceitual, ressaltando que o estrutural e o escultural estão presentes em qualquer tamanho de forma, embora suas categorias de tamanho, idades, gêneses e formas sejam possíveis de ser identificadas e cartografadas separadamente e, portanto, em categorias distintas. A proposta de classificação passa pela concepção de se expressar cartograficamente o relevo, baseada na conceituação de morfoestrutura, para as unidades maiores, e de morfoescultura para as formas e tipos de relevo contidos em cada morfoestrutura existente.

A análise do quadro geomorfológico da área de estudo, bem como sua gênese e dinâmica morfogenética, com base na compartimentação e na estruturação da paisagem local (AB'SABER, 1969), utiliza-se da proposta taxonômica de Ross (1992). Os táxons que serão identificados no mapeamento são: primeiro táxon, que está ligado ao conceito de morfoestrutura, ou seja, aos padrões de formas de influências tectônicas; segundo táxon, que são unidades morfoesculturais, geradas pela ação climática ao longo do tempo geológico na morfoestrutura; terceiro táxon, que apresenta distinção pela fisionomia topográfica, representado por unidades de padrões de formas semelhante ou unidades morfológicas; e quarto táxon, que se refere a cada uma das formas de relevo contidas nas unidades morfológicas e representam as formas de relevo que tanto podem ser por processos de agradação quanto por denudação.

\subsection{Procedimentos Operacionais}

As atividades de pesquisa desenvolvem-se em várias etapas na perspectiva de explicitação dos objetivos deste estudo. Inicia-se pelo levantamento de dados, que compreende o levantamento bibliográfico sobre estudos realizados na área de estudo, como pesquisas geológicas, geomorfológicas, usos da terra, entre outros, bem como a documentação cartográfica referente ao município de Porto Alegre. Inclui-se, nessa etapa, a aquisição de fotografias aéreas e de imagens de satélites de todo o município, bem como a digitalização da base cartográfica, em escala 1:50.000, a partir das cartas topográficas do Serviço Geográfico do Exército (Quadro 1). 
Quadro 1: Documentação Básica para Elaboração do Mapeamento.

\begin{tabular}{|c|c|c|c|}
\hline DENOMINAÇÃO & DATA & FONTE & OBSERVAÇÕES \\
\hline $\begin{array}{c}\text { Imagens de satélite } \\
\text { QuickBird }\end{array}$ & 2002 & $\begin{array}{c}\text { Prefeitura } \\
\text { Municipal de } \\
\text { Porto Alegre }\end{array}$ & Mosaico de Imagens \\
\hline $\begin{array}{c}\text { Fotografias Aéreas } \\
\text { Verticais }\end{array}$ & $1990 / 91$ & METROPLAN & $\begin{array}{c}\text { Cópias em meio } \\
\text { analógico. } \\
\text { Vồ da FAB. }\end{array}$ \\
\hline Cartas Topográficas & 1975 a & DSG & $\begin{array}{c}\text { Folhas } \\
\text { (digitalizadas): } \\
2970 / 3,2970 / 4, \\
2987 / 1,2987 / 2 \\
2987 / 4\end{array}$ \\
\hline $\begin{array}{c}\text { Base altimétrica } \\
\text { vetorial contínua }\end{array}$ & 2010 & Hasenack, Weber \\
$\&$ Lucatelli & $\begin{array}{c}\text { Equidistância } \\
\text { original de 1m, } \\
\text { MNT elaborado com } \\
\text { equidistância de } 5 \mathrm{~m}\end{array}$ \\
\hline
\end{tabular}

O passo seguinte refere-se à elaboração dos mapas morfométricos (clinográfico e hipsométrico) em meio digital e a fotointerpretação das fotografias aéreas na escala de 1:40.000, resultando na criação do mapa de elementos do relevo. Esse mapa representa os aspectos morfológicos da área interpretada e, juntamente com a base cartográfica, o ponto de partida para a construção do mapa geomorfológico.

$\mathrm{O}$ produto da fotointerpretação constituiu-se em um conjunto de estereogramas (um para cada estereopar), contendo os dados para o mapa de elementos do relevo. Esses estereogramas foram georreferenciados, utilizando-se de pontos identificáveis nas aerofotos e na cartografia básica.

Após o georreferenciamento, o material foi digitalizado e validado, visando ao seu uso em sistema de informação geográfica (software ArcGis 9.2). Os trabalhos de campo e revisões da fotointerpretação possibilitaram a consolidação dos polígonos, tanto no que se refere ao seu desenho quanto a sua classificação.

A interpretação de todo o material adquirido é fundamental nos trabalhos de campo, os quais proporcionam checar a fotointerpretação 
realizada e observar as feições de relevo e, também, correlacionar os diferentes padrões de formas de relevo com o uso do solo. Nesse sentido, há a possibilidade, ainda, de fazer registros fotográficos das feições características.

A elaboração da carta final é o resultado da síntese das interpretações a partir das etapas anteriores. O mapa geomorfológico representa, dessa forma, as diferentes unidades de relevo contendo informações sobre a morfologia, morfometria, litologia, uso da terra, morfogênese, morfocronologia, entre outras. Assim, tais informações possibilitam inferir questões de potencialidades e fragilidades ao uso antrópico.

\section{Caracterização Geológica E Geomorfológica Regional}

No âmbito regional, o município de Porto Alegre está localizado numa região de contato entre diferentes unidades morfoesculturais do relevo do Rio Grande do Sul. De acordo com a compartimentação do relevo, proposta por Suertegaray e Fujimoto (2004), em Porto Alegre, evidenciam-se o Planalto Uruguaio Sul-rio-grandense e a Planície e/ou Terras Baixas Costeiras, além dos sedimentos provenientes da Depressão Periférica (Figura 2).

O Planalto Uruguaio Sul-rio-grandense está representado predominantemente por rochas ígneas e metamórficas de idade Pré Cambriana sobre as morfoestruturas do Cráton Rio de La Plata e do Cinturão Orogênico Dom Feliciano. Essas morfoestruturas demonstram na sua dinâmica de formação atividades do Ciclo Brasiliano, período de movimentações regionais durante o afastamento das Plataformas Sul Americana e Africana. O Planalto destaca-se pelos caracteres tectônicos e litológicos de sua formação e por diferentes graus de dissecação. 


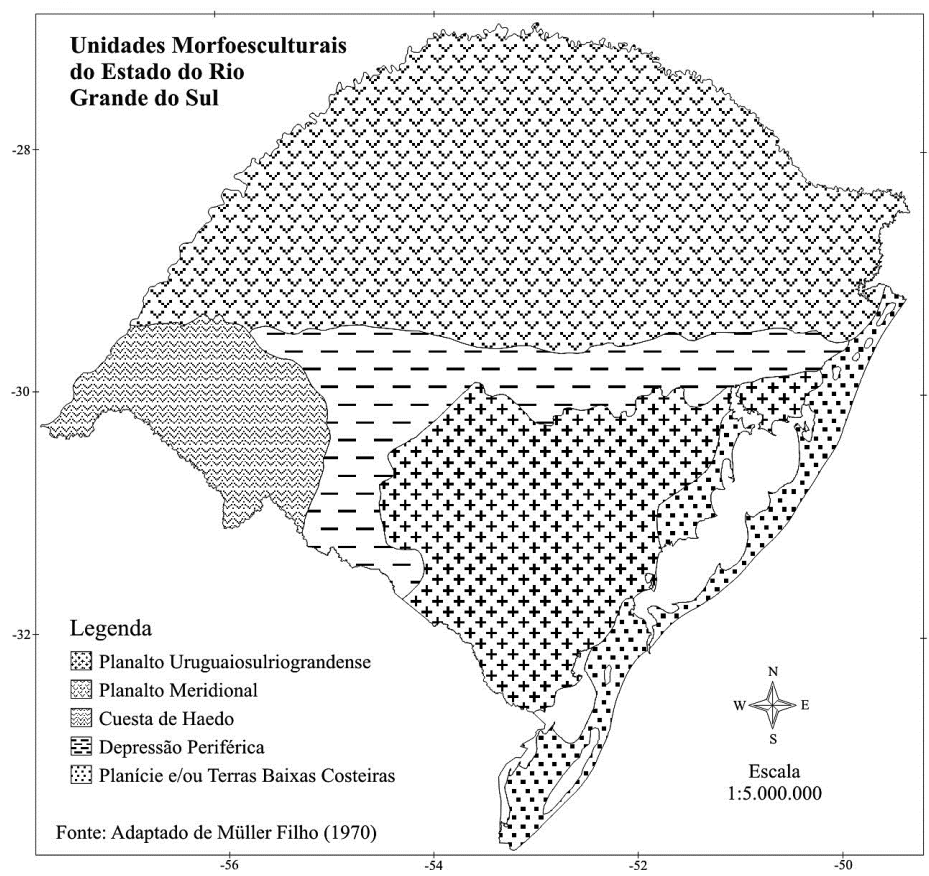

Figura 2: Compartimentação das Unidades Morfoesculturais do Estado do Rio Grande do Sul.

Fonte: SUERTEGARAY e FUJIMOTO (2004).

O Cinturão Dom Feliciano e o Cráton Rio de La Plata serviram de fonte de material para a sedimentação Paleozoica, que veio ocorrer na Depressão Intra-cratônica do Paraná (Bacia do Paraná). Os sedimentos que preencheram essa bacia têm características predominantemente continentais. A disposição desses sedimentos é periclinal, ou seja, mergulham em direção ao eixo da bacia, assinalado aproximadamente pela posição atual dos rios Paraná e baixo-Uruguai. Observa-se que, nesse tempo, esses processos ocorriam em espaço hoje denominado Continente do Gondwana, isto é, quando o continente Africano e Americano constituíam uma única massa continental. A deriva do Gondwana para o norte resultou da colisão, há $270 \mathrm{Ma}$, com a Laurásia, um antigo continente existente no hemisfério norte, vindo a formar a Pangeia.

Quando a Pangeia passou a fragmentar-se, provocou o rompimento do Gondwana, levando à separação da América do Sul e da África e à abertura do Oceano Atlântico (iniciada a $132 \mathrm{Ma}$ ). Grandes falhas 
segmentaram o Gondwana, por onde extravasou enorme volume de lavas que formaram as sucessivas camadas de basaltos do Planalto Meridional do Rio Grande do Sul e adjacentes.

Constitui, por conseguinte, o final da Era Mesozoica, a etapa da evolução geológica mais importante para a compreensão das unidades geomorfológicas atuais no estado Rio Grande do Sul. Os principais fatores responsáveis pela nova configuração da paisagem são: falhamentos que resultaram no soerguimento do Planalto Uruguaio Sul-rio-grandense e do Planalto Meridional; e as oscilações do nível do mar (Quaternário), influenciando na dinâmica dos processos geomorfológicos nesse espaço.

Para melhor compreender essa fase, é importante lembrar que foi provavelmente no médio Jurássico e médio Cretáceo, com a fragmentação do continente de Gondwana, que ocorreu uma série de alinhamentos de falhas e reativações, fundamentais para a individualização das unidades de relevo atuais. Além desses fatores, a fragmentação do antigo continente promoveu também a abertura do Atlântico e, por consequência, uma nova dinâmica na área, derivada agora da proximidade do mar.

A formação da Planície Costeira insere-se nesse contexto e, para compreendê-la, é necessário analisar os principais aspectos estruturais que deram origem à Bacia Sedimentar de Pelotas. Esta se encontra relacionada com os eventos geotectônicos que ocasionaram a abertura do Oceano Atlântico, a partir do Jurássico, e que resultaram na ruptura do bloco continental gondwânico e a posterior separação dos continentes africano e sul-americano (ALMEIDA, 1967 e 1969). A Bacia de Pelotas cobre uma área em torno de $70.000 \mathrm{~km}^{2}$, com limite externo até a isóbata de $200 \mathrm{~m}$. A sua sedimentação teve início com a deposição da sequência do mar, enquanto ocorria o afastamento progressivo das massas continentais sul-americanas e africanas e a formação do piso oceânico a partir da Cordilheira Mesoatlântica (VILLWOCK, 1984).

Na Bacia de Pelotas, são encontradas falhas do embasamento subparalelas à costa e que originaram grandes grabens assimétricos, escalonados e que se aprofundam em direção a leste. Esses são oriundos dos sucessivos basculamentos sofridos pela margem continental, a qual se rompia ao acompanhar a subsidência da costa oceânica adjacente, submetida ao resfriamento. Ao longo desse processo, foram acumulados, durante a Era Cenozóica, mais de 8.00om de sedimentos continentais, transicionais e marinhos. A porção superior dessa sequ- 
ência sedimentar está exposta na Planície Costeira do Rio Grande do Sul em uma ampla área de terras baixas, ocupadas por um grande sistema lagunar.

As variações positivas e negativas do nível do mar têm fundamental importância no estudo da Planície Costeira, pois seu desenvolvimento morfológico e geológico está diretamente relacionado às migrações da linha de praia durante as últimas épocas geológicas, determinando o aparecimento de ambientes costeiros de deposição.

Segundo Villwock e Tomazelli (1995), a Planície Costeira do Rio Grande do Sul tem sua formação associada a períodos regressivos e transgressivos dos últimos períodos geológicos (Cenozoico: período Terciário e Quaternário). Ao longo desses períodos, sucederam-se depósitos continentais e marinhos que originaram uma sequência de sistemas/barreiras. Estas, sucessivamente, isolaram porções de espaço ocupadas pelo mar, que, posteriormente e progressivamente, foram sendo colmatados, dando origem às feições geomorfológicas atuais, bem como à individualização dos sistemas lagunares.

O relevo da Planície e Terras Baixas Costeiras em Porto Alegre está associado predominantemente à deposição lagunar e fluvial, configurando-se em uma área plana, homogênea, sem dissecação, onde dominam os modelados de acumulação representados predominantemente pelas planícies e terraços lacustres e fluviais.

\section{Descrição e Caracterização Do Mapa Geomorfológico}

A descrição da compartimentação das formas de relevo segue a proposta taxonômica de Ross (1992). No âmbito da morfoestrutura o município apresenta duas unidades: o Escudo Uruguaio Sul-rio-grandense, que tem como unidade mofoescultural o Planalto Uruguaio Sul-rio-grandense e a Bacia Sedimentar de Pelotas, representada pela morfoescultura denominada Planície e/ou Terras Baixas Costeiras. A caracterização das feições de relevo na área de estudo baseia-se na caracterização morfométrica, morfológica e suas relações com a litologia, anteriormente analisados por Fujimoto e Dias (2009). A identificação e distribuição de todos os compartimentos do relevo estão representadas no Mapa Geomorfológico do município de Porto Alegre (Figura 3). 


\subsection{Unidade Morfoescultural Planalto Uruguaio Sul- rio-grandense}

O Planalto Uruguaio Sul-rio-grandense destaca-se pelos caracteres tectônicos e litológicos de sua formação e por seus diferentes graus de dissecação, cujas altitudes médias, na região metropolitana de Porto Alegre, estão predominantemente em torno de $50 \mathrm{~m}$ a $100 \mathrm{~m}$. Apresenta-se com uma diversidade morfológica marcadamente em formas de morros e colinas de dimensões variadas, situados no centro do município, formando uma faixa alongada de direção NE-SW, predominantemente. $\mathrm{Na}$ área de estudo, o Planalto está representado por Unidades Morfológicas ou Padrões de Formas Semelhantes, que são: Padrão em forma de morros, em forma de morros associados com colinas, em forma de morros isolados e em forma de colinas. Esses compartimentos situam-se predominantemente na parte central e no limite leste do município e apresentam as maiores altitudes e declividades de Porto Alegre.

\section{Padrão em Forma de Morros}

O padrão em forma de morros é constituído por rochas graníticas geradas durante os estágios de evolução do Cinturão Orogênico Dom Feliciano. Esse cinturão foi originado pela colisão entre dois antigos continentes, um sul-americano e outro africano, que está representado por uma associação de rochas alongadas de direção predominante NE-SW.

Esse compartimento é formado por um conjunto de morros com topos convexos e alguns aguçados, configurando cristas. Apresenta as maiores elevações do município, com altitudes predominantes entre 210 a $240 \mathrm{~m}$ (elevação máxima de $311 \mathrm{~m}$ ) e declividades entre 10 a $20 \%$ (Figura 8). As vertentes apresentam segmento predominantemente retilíneo-côncavo. Nesse padrão, encontram-se as nascentes dos cursos d'água, tendo uma rede de drenagem caracterizada predominantemente por arroios com vales bem entalhados, em forma de V. Os topos e as altas vertentes dos morros são, em sua maioria, áreas pouco ocupadas pelas moradias urbanas e, de modo geral, apresentam vegetação exuberante na vertente voltada para o sul e cobertura vegetal de menor porte na vertente norte, na qual também ocorrem áreas de rocha exposta.

Esse conjunto de formas de relevo é constituído basicamente por rochas graníticas e de sedimentos procedentes do granito. Os solos são classificados como Neossolos Litólicos, pois são rasos e com grande in- 
cidência de afloramentos rochosos, matacões de grandes dimensões, que aparecem nas altas e médias vertentes, enquanto que os solos relativamente profundos são encontrados, predominantemente, na baixa vertente, associados aos segmentos côncavos. Os topos e as altas vertentes dos morros apresentam estrutura físico-química de desagregação/ decomposição através de fraturas e esfoliação esferoidais, retrabalhando os matacões e as rochas expostas.

\section{MAPA GEOMORFOLÓGICO DO MUNICÍPIO DE PORTO ALEGRE - RS}

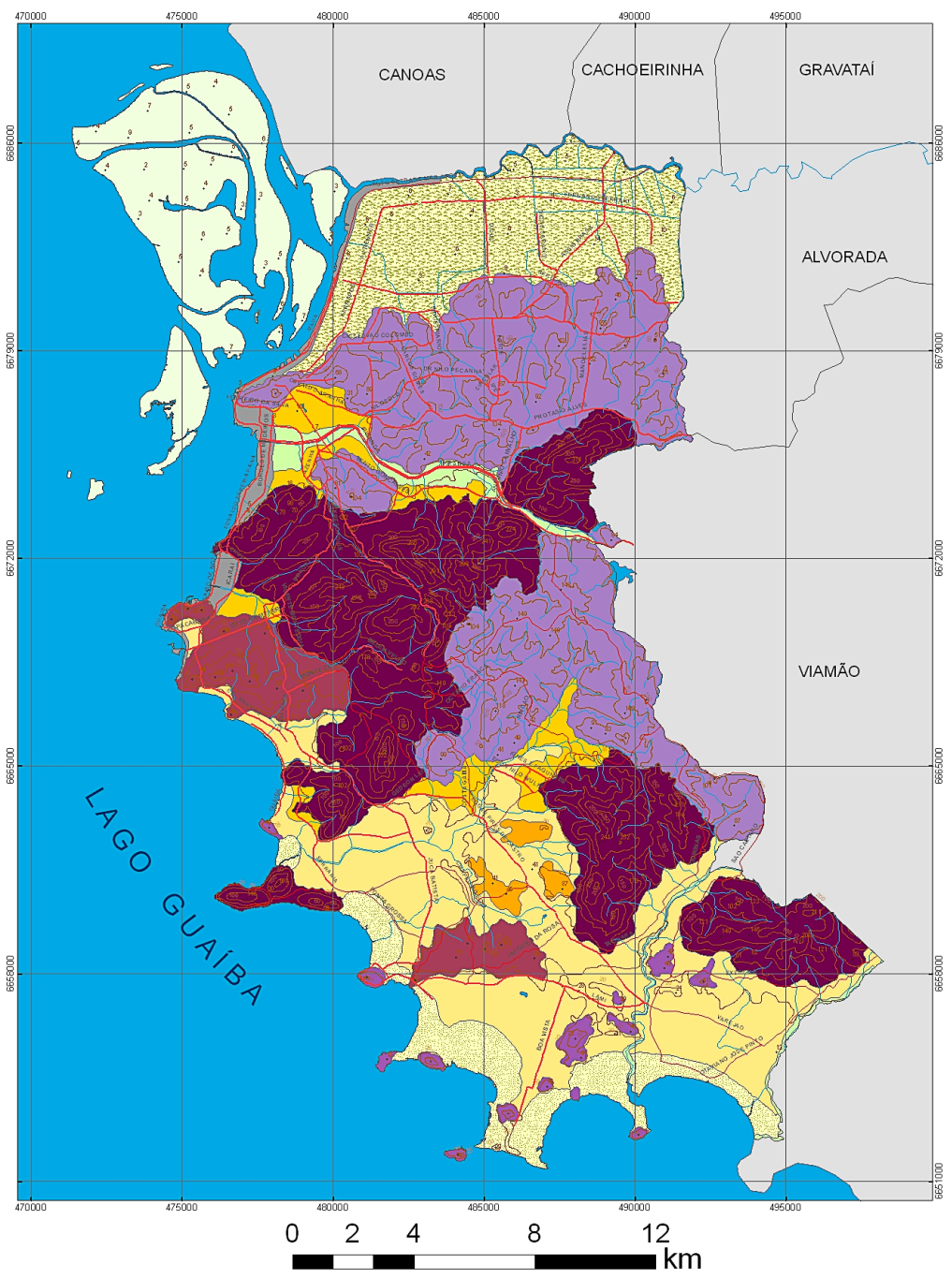




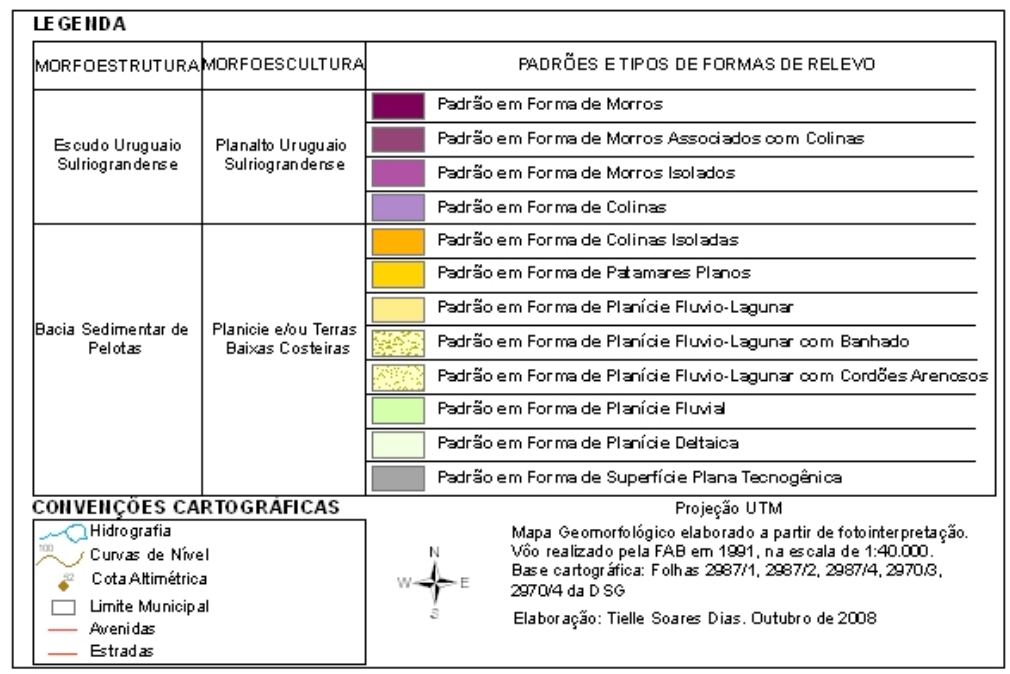

Figura 3: Mapa Geomorfológico de Porto Alegre - RS.

\section{Padrão em Forma de Morros Associados com Colinas}

Esse compartimento de morros está associado com formas em colinas e também é constituído por rochas graníticas, geradas durante os estágios de evolução do Cinturão Orogênico Dom Feliciano. No entanto, em alguns segmentos desse compartimento, são encontradas significativas rampas coluvionares, com declividades médias de 2 a $5 \%$, as quais se caracterizam por depósitos originados por processos gravitacionais e/ ou originados de alteração in situ do embasamento cristalino.

Esse padrão é formado por um conjunto de morros com topos convexos associados com formas em colinas, com topos predominantemente convexos, cujas altitudes médias estão entre os intervalos de 30 a $60 \mathrm{~m} \mathrm{e}$ 60 a 9om. As declividades médias estão predominantemente nas classes de 2 a $5 \%$ e de 5 a 10\%. Caracteriza-se pela associação de morros e colinas de difícil delimitação entre essas duas feições. As vertentes apresentam segmento predominantemente convexo-côncavo. Os segmentos côncavos situam-se preferencialmente nas médias e nas baixas vertentes e estão associados às nascentes dos cursos d'água (Figura 4).

Esse conjunto de formas de relevo é constituído basicamente por rochas graníticas e de sedimentos procedentes do granito. Os solos são classificados como Neossolos Litólicos, pois são rasos e com grande incidência de afloramentos rochosos, matacões de grandes dimensões 
que aparecem nas altas e médias vertentes, enquanto que os solos relativamente profundos são encontrados, predominantemente, na baixa vertente, associados aos segmentos côncavos.

\section{Padrão em Forma de Morros Isolados}

Os morros isolados também são formados por rochas graníticas geradas durante estágios da evolução do Cinturão Orogênicas Dom Feliciano. Esses morros encontram-se isolados entre si devido às variações do nível do mar que ocorreram no Quaternário e dos sucessivos eventos trans-regressivos marinhos. Nesse período, o mar invadiu grandes áreas de Porto Alegre, deixando emersos apenas os morros. O conjunto de morros que, no passado, pertencia ao grande conjunto granítico localizado na área central do município, atualmente, apresenta isolado devido ao preenchimento dos antigos vales por sedimentos depositados durante a transgressão marinha. Com o restabelecimento do nível do mar, ficam evidentes os depósitos sedimentares que isolaram os morros. O aspecto morfológico mais característico desse compartimento é apresentar formas arredondadas ou alongadas, com topos convexizados e vertentes com segmento retilíneo-côncavo. As altitudes são menos elevadas que os demais morros do município, situando-se entre o intervalo de 30 a $60 \mathrm{~m}$, com declividades predominantes entre 5 a $10 \%$.

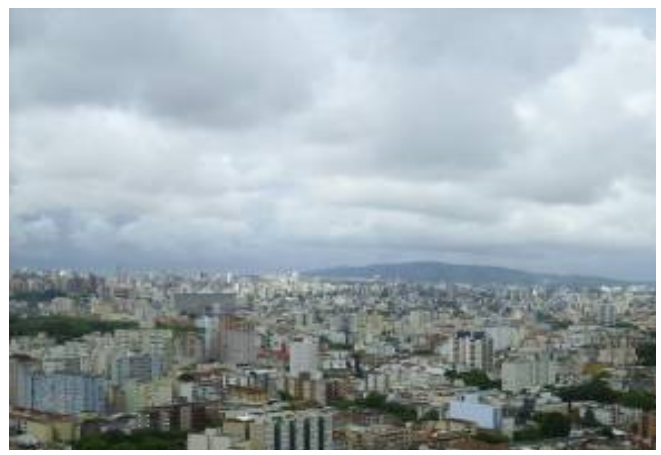

Figura 4: Vista da região central de Porto Alegre, localizada sobre o Padrão em Forma de Colinas e, ao fundo (sul do município), o Padrão em Forma de Morros (19 de janeiro de 2011).

Esse conjunto de formas de relevo é constituído basicamente por rochas graníticas e de sedimentos procedentes do granito. Os solos são 
classificados como Neossolos Litólicos, pois são rasos e com grande incidência de afloramentos rochosos, matacões de grandes dimensões que aparecem nas altas e médias vertentes, enquanto que os solos relativamente profundos são encontrados, predominantemente, na baixa vertente, associados aos segmentos côncavos.

\section{Padrão em Forma de Colinas}

Esse padrão em formas de colinas também é formado por um conjunto de rochas do Cinturão Orogênico Dom Feliciano. As rochas graníticas e os migmatitos que sustentam as colinas têm características texturais e estruturais que geram grandes facilidades para a percolação de águas e, consequentemente, propício à intensificação dos processos de intemperismo e de entalhamento fluvial. Nesse sentido, pode-se compreender a diferenciação entre as formas de relevo em colinas com altitudes e declividades moderadas, sob o manto de alteração extremamente profundo, e as formas de relevo em morros com altitudes e declividades elevadas, sob manto de alteração, no geral, pouco desenvolvido.

De idade Cenozoica, esse padrão é formado por um conjunto de colinas de topos convexos e vertentes com segmento predominantemente convexo-côncavo. Dentro desse padrão, distinguem-se colinas com interflúvios médios e amplos. As colinas com interflúvios médios apresentam vales fechados (em V) e situam-se na parte central do município (divisa com o município de Viamão), apresentando altitudes predominantes entre 40 a $80 \mathrm{~m}$ e declividades entre 5 a $10 \%$. As colinas com interflúvios amplos e vales abertos (em fundo chato), localizam-se ao norte do município e apresentam altitudes predominantes entre 20 a $60 \mathrm{~m}$ e declividades entre o a $2 \%$.

Esse conjunto de formas de relevo é constituído por rochas de composição granítica e de migmatitos que, no contato com os granitos, apresentam características transicionais e interconectadas. Também apresentam depósitos eluvionares, compostos de areias grossas, avermelhadas, mal selecionadas, com matriz síltico-argilosa de origem pedogenética. Os solos são classificados como Argissolos Vermelhos e Argissolos Vermelho-amarelos, caracterizados como solos profundos que apresentam horizontes A, B e C, de ocorrência predominante em relevo ondulado ou levemente ondulado. 


\subsection{Unidade Morfoescultural Planície ou Terras Baixas Costeiras}

A Planície ou Terras Baixas Costeiras está representada por padrões de formas semelhantes que são: Padrão em forma de colinas isoladas, em forma de patamares planos, em forma de planícies flúvio-lagunares, em forma de planície flúvio-lagunares com banhados, em forma de planícies flúvio-lagunares com cordões arenosos, em forma de planícies fluviais, em forma de planícies deltaicas e em forma de superfície plana tecnogênica. Tais padrões estão localizados principalmente na parte norte, oeste e sul do município e correspondem às menores altitudes e declividades de Porto Alegre.

\section{Padrão em Forma de Colinas Isoladas}

As colinas correspondem aos sedimentos arenosos depositados em virtude dos movimentos de transgressão e regressão do nível do mar no Pleistoceno. Esse conjunto de formas de relevo é constituído por sedimentos eluvionares e coluvionares que ocorrem nas proximidades dos morros de Porto Alegre. As condições climáticas atuais permitiram uma estabilização dos sedimentos com ativação dos processos pedogenéticos, convexização das vertentes, entalhamento fluvial e gravitacional/pluvial. Os solos predominantes nesse compartimento são classificados como argissolos vermelhos e argissolos vermelho-amarelos, caracterizados como solos profundos que apresentam horizontes A, $\mathrm{B}$ e C, de ocorrência predominante em relevo ondulado ou levemente ondulado.

A morfocronologia aponta o Padrão em Forma de Colinas Isoladas como sendo do Pleistoceno/Holoceno e apresentando formas em colinas constituídas de sedimentos arenosos recentes. As altitudes predominantes encontram-se entre 20 a $40 \mathrm{~m}$. As declividades predominantes estão na faixa entre 2 a $5 \%$. São colinas com vertentes convexizadas com baixa densidade de drenagem. Ocorre uma suave ruptura topográfica entre as colinas e as áreas de planície adjacentes.

\section{Padrão em Forma de Patamares Planos}

O padrão em forma de patamares planos é constituído, de modo geral, por terraços fluviais, os quais representam antigas planícies de 
inundação que foram abandonadas. Esse padrão apresenta formas em patamares aplainados, de largura variada, um pouco mais elevada que as áreas de planícies fluviais adjacentes. Tais patamares, por vezes, ocorrem de modo semelhante ao longo das vertentes opostas do vale e, por outras, de maneira isolada, ou seja, ocorrem em apenas um dos lados do vale. As altitudes estão em torno dos $20 \mathrm{~m}$ e a declividade é menor que $2 \%$.

Esse conjunto de formas de relevo é constituído por depósitos eluvionares de areias médias a grossas, mal selecionadas, com origem pedogenética, com formas de conglomerado, em alguns locais recobertos por manto coluvional e aluvial. De origem holocênica e pleistocênica, esses depósitos estão associados aos Sistemas laguna-barreira (depósitos eluvionares e terraços fluviais). Os solos são classificados como planossolos hidromórficos, gleissolos háplicos e plintossolos argilúvicos, caracterizados por serem mal drenados, localizados em áreas de várzea, com um relevo plano a suavemente ondulado.

\section{Padrão em Forma de Planícies Flúvio-lagunares}

A formação das Planícies Flúvio-lagunares ocorreu a partir dos depósitos sedimentares originários principalmente da segunda grande transgressão marinha, ocorrida no pleistocênico, que ligaram Porto Alegre ao continente por áreas planas alagadiças e terraços arenosos. Além da deposição através da variação do nível do mar, originando formas trabalhadas pela ação lagunar (da laguna dos Patos), houve a estruturação dos canais fluviais, presentes nesse compartimento, a partir da formação dos terraços fluviais.

De idade Holocênica, esse padrão compreende uma extensa área plana com cotas altimétricas inferiores aos $20 \mathrm{~m}$ e com declividades menores que $2 \%$. Estendem-se em direção sudeste-noroeste, acompanhando a transição dos morros até a orla do Guaíba. Apresenta ondulações suaves e são entrecortadas por colinas isoladas, planícies fluviais, morros isolados e morros associados com colinas (Figura 5). 


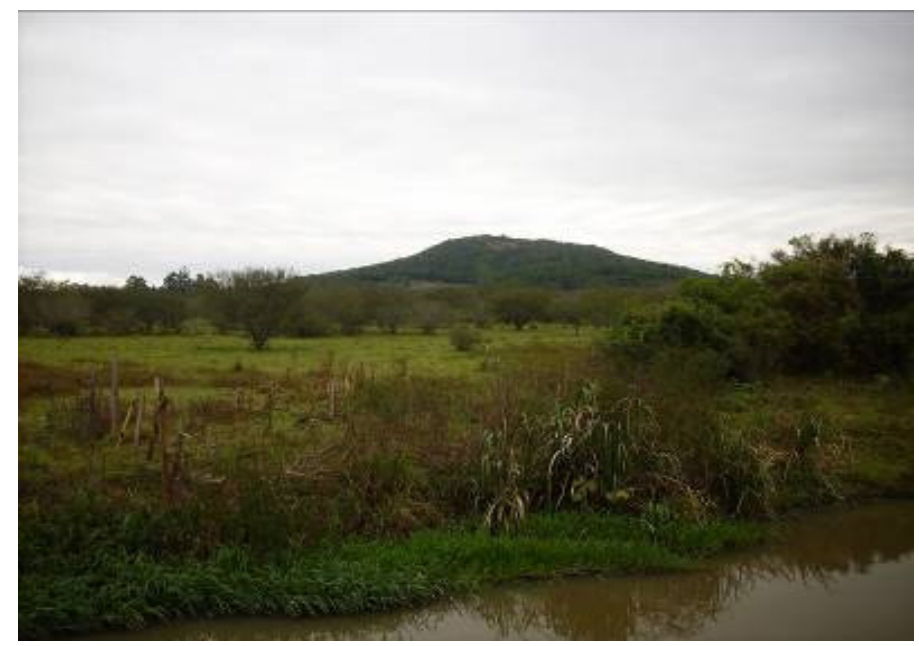

Figura 5: Planície Fluvial do Arroio do Salso, adjacente às planícies flúvio-lagunares no bairro Serraria, zona sul de Porto Alegre. Ao fundo, morro isolado (19 de maio de 2009).

Esse conjunto de formas de relevo é constituído por sedimentos argilo-areno-conglomerático e conglomerático. Localmente recobertos por manto coluvional e aluvial de paleossolos ferralíticos, são depósitos de fluxo de detritos, associado também a depósitos lacustres. Os solos são classificados como Planossolos Hidromórficos, Gleissolos Háplicos e Plintossolos Argilúvicos, caracterizados por serem mal drenados, localizados em áreas de várzea, com um relevo plano a suavemente ondulado.

\section{Padrão em Forma de Planície Flúvio-lagunar com Banhados}

O sistema deposicional Laguna-barreira, ocorrido no Holoceno, isolou essa área em depressão, ficando representada pelo Sistema Lagunar Guaíba-Gravataí. A posterior sedimentação trazida pelos rios transformou essa depressão em um ambiente de sedimentação fluvial, lagunar e paludal e, posteriormente, importantes depósitos turfáceos se desenvolveram.

De idade Holocênica, esse padrão configura-se em uma extensa área plana, localizada ao norte do município, apresenta cotas altimétricas inferiores aos $20 \mathrm{~m}$ e com declividades menores que $2 \%$. A rede de drenagem é representada pelos banhados e por canais retilinizados (Figura 6). 


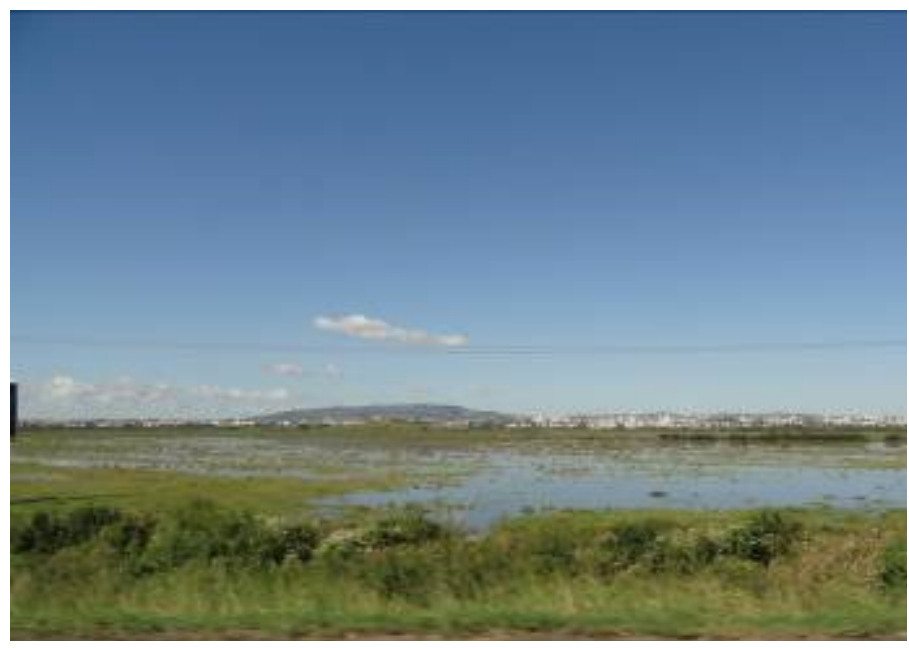

Figura 6: Padrão em Forma de Planície Flúvio-Lagunar com Banhado localizado ao norte do município, próximo à BR 290 (24 de abril de 2011).

Esse conjunto de formas de relevo é constituído por depósitos de planície associados aos canais fluviais, contendo areias grossas e conglomeráticas. Os solos são classificados como gleissolos, planossolos localizados em áreas de acumulação de água, são caracterizados como um ambiente que evidencia a ausência de oxigênio, propiciando processos de acumulação de material orgânico e intensa redução química.

\section{Padrão em Forma de Planícies Flúvio-lagunares com Cordões Arenosos}

A formação da Planície Fluvio-lagunar com Cordões Arenosos ocorreu a partir dos depósitos sedimentares, originária da quarta e última grande transgressão marinha ocorrida no Holoceno. A progressiva regressão marinha favoreceu a constituição de barreiras, consequentemente, das planícies com cordões arenosos, localizadas ao sul do município, que acompanham a margem do Guaíba. As enseadas do Guaíba estão relacionadas à circulação interna das águas e consequente erosão e deposição dos sedimentos.

De idade Holocênica, esse padrão compreende uma superfície extremamente plana, com pequenas áreas alagadas, cordões arenosos e dunas estáveis, dispostas paralelamente às enseadas e/ou linhas de praia do Guaíba. As declividades são menores que $2 \%$ e as altitudes menores que 20 metros. A rede de drenagem é densa e significativa nesse com- 
partimento. Arroios de regime fluvial perene nascem nas altas vertentes dos morros, atravessando essa unidade até desaguar no Guaíba.

Esse conjunto de formas de relevo é constituído por depósitos holocênicos representados por sedimentos areno-argilosos, com areias de grossas a finas, moderadamente selecionadas, que ocorrem em forma de feixes de restinga às margens do Guaíba. Os solos são classificados como neossolos quartzarênicos e gleissolos, caracterizados por serem profundos e possuírem horizontes A-C, todos de textura muito arenosa. Variam de solos bem a mal drenados, dependendo da sua configuração topográfica: superfície elevada ou rebaixada, respectivamente.

\section{Padrão em Forma de Planícies Fluviais}

De idade Holocênica, esse padrão consiste em uma área plana, com declividades inferiores a $2 \%$, situada ao longo de trechos de alguns arroios do município. São áreas com sedimentos decorrentes da erosão e deposição fluvial, que possuem altitudes predominantes inferiores a 20 metros.

Esse conjunto de formas de relevo é constituído por areias grossas e conglomeráticas, decorrentes da ação fluvial. Os solos são classificados como planossolos hidromórficos, gleissolos haplicos e neossolos flúvicos, originados de sedimentos fluviais, os quais compõem uma estratificação de granulometria variável, apresentam horizontes A-C, com a presença irregular de matéria orgânica.

\section{Padrão em Forma de Planícies Deltaicas}

O processo de formação das Planícies Deltaicas ocorreu pelo aporte de sedimentos originários da quarta grande transgressão marinha do Holoceno e de sedimentos vindos dos cursos d'água que deságuam no lago Guaíba. Os rios Jacuí, Sinos, Caí e Gravataí, ao desaguarem no Guaíba (um grande reservatório de água), diminuem a sua competência, ocorrendo depósito de material areno-argiloso, formando bancos submersos de areia e lama. Esses bancos evoluem até formar ilhas recortadas por inúmeros canais distributários.

De idade Holocênica, esse padrão é composto por um conjunto de oito grandes ilhas e de oito ilhas menores, localizadas no delta do rio Jacuí. São áreas planas, com declividade inferior a $2 \%$, onde são encontradas as mais baixas altitudes do município, menos de 10 metros. São 
áreas de terras baixas, alagadiças, com canais anastomosados, apresentam areias inconsolidadas de idade holocênica. Em seu interior, existem banhados, meandros abandonados e indícios de paleocanais.

Esse conjunto de formas de relevo é constituído por areias grossas e finas e de argila, correspondentes aos depósitos deltaicos provenientes, predominantemente da Depressão Periférica. Variam em tonalidades de amareladas a pretas, moderadamente selecionadas, com abundantes restos vegetais. Os solos são classificados como Gleissolos e Neossolos flúvicos, originados de sedimentos fluviais, com uma estratificação de granulometria variável, são profundos, mal drenados e com deficiência de oxigênio, propiciando acumulação de material orgânico.

\section{Padrão em Forma de Superfície Plana Tecnogênica}

$\mathrm{O}$ aterro de Porto Alegre foi construído pela deposição de material retirado de outras áreas e do remanejamento de material do próprio local. Segundo Souza e Müller (2007), a sua construção teve início a partir do século XIX, com algumas pequenas faixas de terra reduzindo o lago Guaíba. O aterro ainda prossegue, sendo que, em 1990, a área central equivalia ao triplo da área inicial (Figura 7).

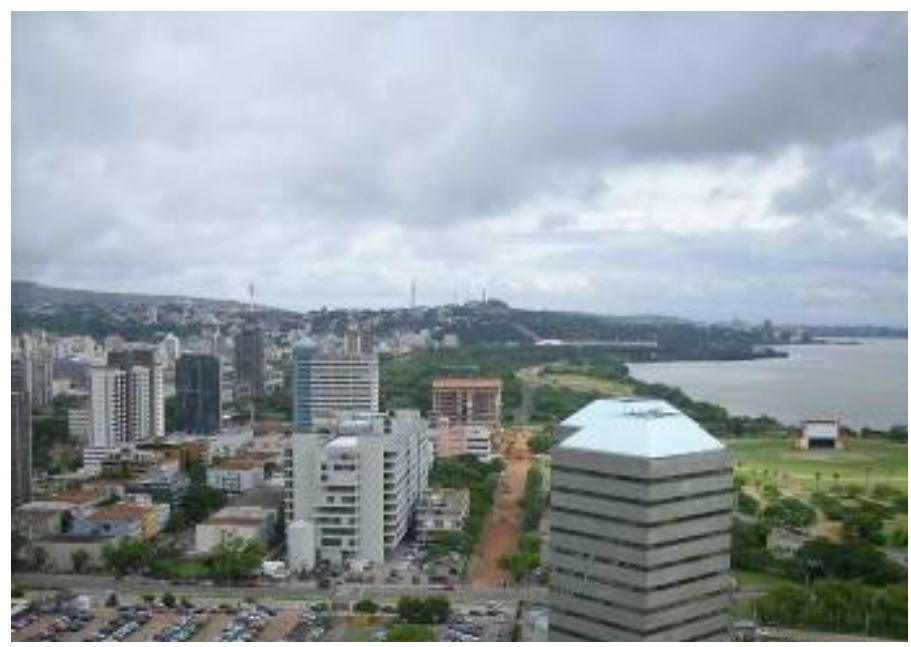

Figura 7: Área central de Porto Alegre, localizada sobre o Padrão em Forma de Superfície Plana Tecnogênica (aterro) adjacente ao Guaíba. Ao fundo o Padrão em Forma de Morros e de Morros associados com Colinas, na zona sul do município (19 de janeiro de 2011). 
Esse padrão é composto por uma alongada faixa plana, criada à margem leste do Guaíba. É uma forma construída a partir do aterramento e retilinização da orla. Configura-se em uma superfície plana com declividade inferior a $2 \%$ e altitudes de, no máximo, 30m. Esse conjunto de formas de relevo é constituído por depósitos tecnogênicos (predominantemente de depósitos arenosos). Os solos são classificados como tipo de terreno ou tecnogênicos, estando associados à alteração pela ação humana, na forma de áreas de empréstimo (aterro).

\section{Considerações Finais}

O Mapa Geomorfológico permitiu contextualizar o município de Porto Alegre no quadro geológico e geomorfológico regional, bem como proporcionar a obtenção de características morfológicas, morfométricas, litológicas e morfocronológicas fundamentais em um único documento de síntese.

A análise dos padrões de relevo permitiu reconhecer os tipos de relevo e os processos a eles relacionados, buscando compreender como os processos articulam-se entre si e como evoluem os grandes conjuntos de formas de relevo. Nesse sentido, é possível vislumbrar o significado do relevo no contexto ambiental, pois um estudo geomorfológico preocupado com os processos passados e presentes na constituição do relevo caracteriza o funcionamento das diferentes paisagens e torna possível compreender o funcionamento dos processos e prognosticar vários aspectos do seu comportamento. Segundo Argento (1994:366), "nos projetos de gerenciamento ambiental ou até mesmo numa concepção mais integradora, como de gestão do território, os mapeamentos em base geomorfológica têm sido priorizados...", pois as formas refletem um comportamento dinâmico da paisagem, do passado ao presente, estando sujeitas a ajustes em seu modelado, como resultado de suas relações com os processos que atuam sobre ela.

Buscar o significado do relevo no contexto ambiental permite visualizar o conjunto de fatos integrantes da paisagem e possibilita a realização de análises para avaliar os diferentes graus de interferência e de inter-relações das variáveis que caracterizam um determinado quadro natural. Um mapeamento sistemático das feições geomorfológicas, de acordo com a proposta taxonômica de Ross (1992), facilita uma avaliação pouco mais precisa das prováveis tendências evolutivas do ambiente. 
Esse mapeamento (realizado com intuito de tornar-se um documento de base) pode ser utilizado em outros estudos que necessitam conhecer os mecanismos de funcionamento das diversas unidades da paisagem, com o intuito de contribuir no planejamento e gestão do território.

6. Referências Bibliográficas

AB'SABER, A. N. Um conceito de Geomorfologia a Serviço das Pesquisas sobre o Quaternário. Geomorfologia, 18, IGEO-USP, São Paulo, 1969.

AB'SABER, A. N.\& ROCHE, J. Três estudos rio-grandenses. Universidade Federal do Rio Grande do Sul Faculdade de Filosofia, Porto Alegre, 1966.

ALMEIDA, F.F.M. Diferenciação Tectônica da Plataforma Brasileira. Anais do XXIII Congresso Brasileiro de Geologia, Salvador, 1969, 29-46p.

ALMEIDA, F.F.M. Origem e Evolução da Plataforma Brasileira. Boletim da Divisão de Geologia e Mineralogia, n ${ }^{\circ}$ 241, Rio de janeiro, 1967 , 1-36p.

ARGENTO, S. A. Mapeamento Geomorfológico. In: GUERRA, A. J. T. \& CUNHA, S. B. Geomorfologia: uma atualização de bases e conceitos. Editora Bertrand Brasil, Rio de Janeiro, 1994, 365-391p.

FERNANDES, L. A. D; MENEGAT, R.; COSTA, A. F. U; KOESTER, E; PORCHER, C. C.; TOMMASI, A.; KRAEMER, G.; RAMGRAB, G. E. , CAMOZZATO, E. Evolução Tectônica do Cinturão Dom Feliciano no Escudo Sul-rio-grandense: Parte II - uma contribuição a partir das assinaturas geofísicas. Revista Brasileira de Geociências, 1995, 25 (4): 375-384p.

FRAGOSO-CESAR, A.R.S.; WERNICK, E., SOLIANI Jr., E. Evolução Geotectônica do Cinturão Dom Feliciano - Uma Contribuição através da Aplicação do Modelo de Tectônica de Placas. Anais do XXXII Congresso Brasileiro de Geologia (vol.1), Salvador, 1982a, 13-23p.

FRAGOSO-CESAR, A.R.S.; WERNICK, E. , SOLIANI Jr., E. Associação Petrotectônicas do Cinturão Dom Feliciano (SE da Plataforma Sul-Americana). Anais do XXXII Congresso Brasileiro de Geologia (vol.ı), Salvador, 1982b, 1-12p. 
FUJIMOTO, N. S. V. M. Análise Geomorfológica de Itapuã - RS: Contribuição ao Conhecimento da Margem Norte da Laguna dos Patos. Dissertação de Mestrado apresentada a Faculdade de Filosofia, Letras e Ciências Humanas da Universidade de São Paulo, São Paulo, 1994, $175 \mathrm{p}$.

FUJIMOTO, N.S.V.M. \& DIAS, T. S. Compartimentos de Relevo do Município de Porto Alegre, capital do estado do Rio Grande do Sul - Brasil. Anais do $12 \mathrm{ffl}$ Encuentro de Geógrafos de America Latina, Montevideo, Uruguay, 2009. 15p.

FUJIMOTO, N.S.V.M. \& SCHIMITZ, C. M. Mapeamento Geomorfológico Aplicado a Análise Ambiental do Município de Viamão - RS. Revista Ciência e Natura - Edição Especial, Santa Maria, 2004, 219-233p.

FUjIMOTO, N.S.V.M. Análise Ambiental Urbana na Área Metropolitana de Porto Alegre - RS: Sub-Bacia Hidrográfica do Arroio Dilúvio. Tese de Doutorado apresentada a Faculdade de Filosofia, Letras e Ciências Humanas da Universidade de São Paulo, São Paulo, 2001, 236p.

HASENACK, H.; WEBER, E.J.; LUCATELLI, L.M.L. 2010. Base altimétrica vetorial contínua do município de Porto Alegre-RS na escala 1:1.000 para uso em sistemas de informação geográfica. Porto Alegre, UFRGS-IB-Centro de Ecologia. ISBN 978-85-63843-03-6. Disponível em http://www.ecologia.ufrgs.br/labgeo

MENEGAT, R.; PORTO, M.L.; CARRARO, C.C. e FERNANDES, L.A.D. Atlas Ambiental de Porto Alegre. Editora da Universidade, Porto Alegre, 1998, 228p.

MÜLLER FILHO, I. L. Notas para o estudo da Geomorfologia do Estado do Rio Grande do Sul. Brasil. Departamento de Geociências, UFSM. Publicações Especiais. Nffl 1, Santa Maria, 1970, 34p.

PHILIPP, R. P.; NARDI, L. V. S.; MACHADO, R.. O Magmatismo Granítico Neoproterozóico Tardi a Pós-Colisional da Região de Porto Alegre, RS. In: CONCEIÇÃO, H.; CRUZ, M.J.M.; SÁ, J.H.S, SABATÉ, P. (Eds.). Contribuição ao Estudo dos Granitos e Rochas Correlatas. Publicação Especial n. 5, Salvador, 1998, 129-152p. 
ROSS, J.L.S. O Registro Cartográfico dos Fatos Geomorfológicos e a Questão da Taxonomia do Relevo. Revista do Departamento de Geografia, 6, FFLCH/USP, São Paulo, 1992, 17-29p.

SOUZA, C. F. de, MÜLLER, D. M. Porto Alegre e sua Evolução Urbana. Porto Alegre: Editora da UFRGS, 2007. 68-69p.

SUERTEGARAY, D. A. A. Rio Grande do Sul: Morfogênese da Paisagem: Questões para a Sala de Aula. Boletim Gaúcho de Geografia, $n^{\circ} 21$, Porto Alegre, 1996, 117-132p.

SUERTEGARAY, D. M. A. \& FUJIMOTO, N. S. V. M. Morfogênese do relevo do Estado do Rio Grande do Sul. In: VERDUM, R., BASSO, L. A., SUERTEGARAY, D. M. A. (Orgs.) Rio Grande do Sul: paisagens e territórios em transformação. Porto Alegre: Editora da UFRGS, 2004. 11-26p.

VILLWOCK, J. A. \& TOMAZELLI, L. J. Geologia Costeira do Rio Grande do Sul. Notas Técnicas, n 8 , Centro de Estudos de Geologia Costeira e Oceânica, Instituto de Geociências, UFRGS, Porto Alegre, 1995, 45p.

VILLWOCK, J. A. Geology of the Coastal Province of Rio Grande do Sul, Southern Brasil Synthesis. Pesquisa, 6, Instituto de Geociências da UFRGS, Porto Alegre, 1984, 1-54p.

Submetido em: 22/05/2011

Aceito em: 12/09/2011 